\title{
Estandarización de una Técnica de PCR en Tiempo Real con Sondas TaqMan para la Detección de Leptospira spp Patógenas en Orina de Canes Domésticos
}

\author{
Standardization of a Real Time PCR TaqMan Assay for Detection of \\ Pathogenic Leptospira SP in URine of Dogs
}

\author{
André Sedano S. ${ }^{1}$, Chris E. Pinto J. ${ }^{1}$, Juan Siuce M. ${ }^{1}$, Sonia Calle E. ${ }^{1,2}$
}

\section{RESUMEN}

El presente estudio tuvo como objetivo estandarizar una técnica de PCR en tiempo real con sondas TaqMan para detectar la presencia de leptospiras patógenas en orina de perro infectada in vitro con cepas patrón de Leptospira sp. Las muestras fueron obtenidas de un perro clínicamente sano y negativo a la prueba de microaglutinación. Se utilizaron los cebadores Lepto R y Lepto F, específicos para Leptospira sp y una sonda TaqMan Lepto probe que amplifican e hibridan, respectivamente, una porción del gen rrs, capaces de diferenciar entre especies patógenas y no patógenas de Leptospira. Se estandarizó el protocolo de PCR en 35 ciclos, con un proceso de desnaturalización inicial a $95^{\circ} \mathrm{C}$ por $5 \mathrm{~min}$, seguida por una desnaturalización a $95{ }^{\circ} \mathrm{C}$ por $15 \mathrm{~s}$ y finalmente el alineamiento y extensión en un solo paso a $60{ }^{\circ} \mathrm{C}$ por $1 \mathrm{~min}$. Los valores de ciclo umbral $(\mathrm{Ct})$ determinados durante la estandarización de la PCR estuvieron en un rango de 12.53 a 18.21 para las 25 cepas patógenas de Leptospira sp, en tanto que las cepas saprófitas y otros bacterias no dieron productos específicos. El estándar fue detectado hasta una dilución de $10^{2}$ con un Ct de 29.98 a una eficiencia de 1.13 y con un coeficiente de correlación $\left(\mathrm{R}^{2}\right)$ de 0.993 . Se detectó ADN en las muestras de orina infectada desde la dilución de $10^{7}$ leptospiras/ml con un valor de $\mathrm{Ct}$ de 17.54 hasta una mínima dilución de $10^{2}$ leptospiras/ml con un valor de Ct de 29.87 .

Palabras clave: canes domésticos, PCR en tiempo real, sondas TaqMan, Leptospira sp, leptospirosis, orina

\footnotetext{
${ }^{1}$ Laboratorio de Microbiología y Parasitología Veterinaria. Facultad de Medicina Veterinaria, Universidad Nacional Mayor de San Marcos, Lima, Perú

${ }^{2}$ E-mail: calleson@gmail.com
} 
This study aimed to standardize a TaqMan Real-Time PCR assay to detect the presence of pathogenic leptospires in urine samples of a dog infected in vitro with standard strains of Leptospira spp. Samples were obtained from a clinically healthy dog, negative to the microagglutination test. Lepto R and Lepto F primers, specific for Leptospira sp and a Lepto TaqMan probe were used, which amplified and hybridized respectively a portion of the rrs gene, differentiating between pathogenic and nonpathogenic species of Leptospira. Thermocycling program was standardized with 35 cycles of $95^{\circ} \mathrm{C}$ for $15 \mathrm{~s}$ and $60{ }^{\circ} \mathrm{C}$ for $1 \mathrm{~min}$ with an initial cycle of $95^{\circ} \mathrm{C}$ for $5 \mathrm{~min}$. Cycle threshold $(\mathrm{Ct})$ values determined during the standardization of PCR were from 12.53 to 18.21 for the 25 pathogenic strains of Leptospira sp. In contrast, saprophytic Leptospira and other species of bacteria did not produce any specific $\mathrm{Ct}$ value. The standard strain was detected up to a dilution of $10^{2}$ with a $\mathrm{Ct}$ value of 29.98 at an efficiency of 1.13 and a correlation coefficient $\left(\mathrm{R}^{2}\right)$ of 0.993 . DNA was detected in infected urine samples from the dilution of $10^{7}$ leptospires $/ \mathrm{ml}$ with a $\mathrm{Ct}$ value of 17.54 to a minimum dilution of $10^{2}$ leptospires $/ \mathrm{ml}$ with a Ct value of 29.87 .

Key words: domestic canines, real time PCR, TaqMan probe, Leptospira sp, leptospirosis, urine

\section{INTRODUCCIÓN}

La leptospirosis es una enfermedad zoonótica de gran impacto en la salud pública. Es causada por bacterias del género Leptospira, que afectan al hombre y a casi todas las especies de mamíferos, tanto silvestres como domésticos, siendo los roedores los principales reservorios. Existen más de 200 serovares (Acha y Szyfres, 2003; WHO e ILS, 2003; Navarrete et al., 2006; OMS, 2008; Adler y de la Peña Moctezuma, 2010).

La leptospirosis es considerada una enfermedad endémica, epidémica y reemergente. Se reportan más de 500,000 casos severos anuales con tasas de mortalidad entre el 10 y el $40 \%$ (Hartskeel et al., 2001; Hartskeel, 2005; OMS, 2008). En el Perú, a partir de 2011 se ha observado un incremento de casos, especialmente en 2012 y 2013, con brotes en los departamentos de Loreto y San Martín (Vargas, 2014). Sin embargo, la carga real de la enfermedad está subestimada debido a la deficiente vigilancia epidemiológica, dificultad de diagnóstico y baja sensibilidad de las pruebas diagnósticas convencionales (McBride et al., 2005).

El hombre generalmente se infecta por contacto directo con la orina de animales infectados o indirectamente a través del suelo y agua contaminada con esta orina (Levett, 2001; OMS, 2008). La leptospirosis ha sido tradicionalmente catalogada como enfermedad ocupacional y de ambientes rurales, pero está emergiendo como un problema urbano (Romero y Sánchez, 2009; Mendes et al., 2011), donde el perro podría tener relevancia epidemiológica como reservorio, dada su estrecha relación con el hombre (Blum et al., 2013).

Se han desarrollado pruebas de laboratorio mediante PCR para la detección de leptospiras patógenas en el humano (Smythe et al., 2002; Slack et al., 2007; Ahmed et al., 2009; Rojas et al., 2010). En la fase aguda de la enfermedad, las leptospiras están presentes en grandes cantidades en varios fluidos corporales (sangre, líquido cefalorraquídeo, orina), de allí que se puede obtener buenos resultados en los ensayos de PCR antes de iniciar la terapia antimicrobiana 
(Slack et al., 2007; Ahmed et al., 2009; Villumsen et al., 2010).

Los protocolos de PCR en tiempo real podrían facilitar la detección temprana de leptospiras patógenas en pacientes con síntomas clínicos sugestivos de la enfermedad, así como en la identificación de animales portadores en muestras de orina. Esto sería una ventaja frente a la prueba de aglutinación microscópica (MAT), que es el 'Gold standard' en el diagnóstico de esta enfermedad (Picardeau et al., 2001), dado que MAT no es efectiva antes del sétimo día de la enfermedad (Cole et al., 1973; Céspedes, 2005).

La prueba de MAT tiene, además, limitaciones en el diagnóstico de la infección crónica en animales, en el diagnóstico de abortos y en la identificación de portadores renales o genitales (OIE, 2014). Por otro lado, el cultivo bacteriano es de crecimiento lento, no menor de 13 semanas, siendo ineficaz para un diagnóstico rápido (Musso y La Scola, 2013).

Dentro de los métodos de PCR en tiempo real, en base a su fluorescencia, se encuentran los que utilizan SYBR Green, pero son menos específicos que aquellas que emplean sondas de hibridación, tales como las TaqMan (Merien et al., 1992; Brown et al., 1995; Espy et al., 2006). El objetivo del presente estudio fue implementar y estandarizar una técnica molecular que detecte la presencia de leptospiras patógenas en orina de canes domésticos a través de una técnica de PCR en tiempo real con sondas TaqMan.

\section{Materiales y Métodos}

\section{Lugar de Estudio}

El estudio se llevó a cabo en la Unidad de Diagnóstico Molecular del Laboratorio de Microbiología y Parasitología de la Facultad de Medicina Veterinaria de la Universidad Nacional Mayor de San Marcos (FMVUNMSM), Lima.

\section{Extracción de ADN}

Se optimizaron los protocolos de extracción de ADN bacteriano a partir de cultivos de leptospiras en caldo modificado EMJH $\left(\right.$ Difco $\left.^{\mathrm{TM}}\right)$ y a partir de la orina de un perro sano (negativo a leptospirosis a través de una evaluación clínica y serológica), infectada in vitro con cepas patógenas de Leptospira sp.

\section{Cultivos en medio EMJH}

Para la extracción de ADN se utilizaron cultivos vivos de los 25 serogrupos patógenos establecidos de Leptospira sp y una cepa saprófita de Leptospira biflexa serovar Semaranga (Cuadro 1). Estas cepas fueron obtenidas de la Unidad de Espiroquetas del Instituto Pasteur (París, Francia). Los cultivos fueron utilizados a los 5-7 días de crecimiento.

Se utilizó el kit comercial Wizard® Genomic DNA Purification (Promega), siguiendo el protocolo base, diseñado por el fabricante para bacterias Gram negativas, agregando la enzima lisozima y proteinasa $\mathrm{K}$ en diferentes concentraciones $(50 \mathrm{mg} / \mathrm{ml} \mathrm{y}$ $10 \mathrm{mg} / \mathrm{ml}$, respectivamente). Para la preparación de las muestras, previa a la ejecución del protocolo de extracción, se utilizaron velocidades de 3000 y $16000 \mathrm{~g}$ a 20 y $25 \mathrm{~min}$, respectivamente. Los productos obtenidos fueron almacenados a $-20{ }^{\circ} \mathrm{C}$ hasta su utilización.

\section{Orina infectada experimentalmente}

Para la extracción de ADN de la orina se obtuvieron cinco muestras (una muestra por mes) de un perro (Canis lupus familiaris) sano, menor de un año de edad, sin signos clínicos compatibles con leptospirosis, negativo a la prueba de MAT y sin crecimiento bacteriano en el urocultivo. Se verificó la negatividad a la prueba de MAT del donante antes de la primera muestra y luego de la última muestra, al quinto mes. La muestra fue tomada en frasco estéril durante la micción y los urocultivos se hicieron en todas las muestras de orina. 
Cuadro 1. Serovares de Leptospira utilizados para la estandarización de la técnica de PCR en tiempo real

\begin{tabular}{|c|c|c|c|c|}
\hline $\mathrm{N} .^{\circ}$ & Especie & Serogrupo & Serovar & Cepa \\
\hline 1 & L. interrogans & Australis & Bratislava & Jez-bratislava \\
\hline 2 & L. interrogans & Autumnalis & Autumnalis & Akiyami A \\
\hline 3 & L. borgpetersenii & Ballum & Castellonis & Castellon 3 \\
\hline 4 & L. interrogans & Bataviae & Bataviae & Van Tienen \\
\hline 5 & L. interrogans & Canicola & Canicola & Hond Utrecht IV \\
\hline 6 & L. weilii & Celledoni & $\mathrm{ND}^{1}$ & 2011/01963 \\
\hline 7 & L. kirschneri & Cynopteri & Cynopteri & $3522 \mathrm{c}$ \\
\hline 8 & L. interrogans & Djasiman & Djasiman & Djasiman \\
\hline 9 & L. kirschneri & Grippotyphosa & Grippotyphosa & Moska V \\
\hline 10 & L. interrogans & Hebdomadis & Hebdomadis & Hebdoma dis \\
\hline 11 & L. fainei & Hurstbridge & Hurstbridge & BUT6 \\
\hline 12 & L. interrogans & Icterohaemorrhagiae & Icterohaemorrhagiae & Verdun \\
\hline 13 & L. licerasiae & Iquitos & Varillal & VAR10 \\
\hline 14 & L. borgpetersenii & Javanica & Javanica & Poi \\
\hline 15 & L. noguchii & Louisiana & Louisiana & LUC1945 \\
\hline 16 & L. interrogans & Manhao & Lincang & L14 \\
\hline 17 & L. santarosai & Mini & Georgia & LT117 \\
\hline 18 & L. noguchii & Panama & Panama & CZ 214K \\
\hline 19 & L. interrogans & Pomona & Pomona & Pomona \\
\hline 20 & L. interrogans & Pyrogenes & pyrogenes & Salinem \\
\hline 21 & L. meyeri & Ranarum & Ranarum & ICF \\
\hline 22 & L. weilii & Sarmin & Sarmin & Sarmin \\
\hline 23 & L. interrogans & Sejroe & Hardjobovis & Sponselee \\
\hline 24 & L. santarosai & Shermani & Shermani & $1342 \mathrm{~K}$ \\
\hline 25 & L. borgpetersenii & Tarassovi & Tarassovi & Perepelitsin \\
\hline 26 & L. biflexa & Semaranga & Patoc & Patoc 1 \\
\hline
\end{tabular}

La infección in vitro de la orina se realizó agregando $100 \mu 1$ de cultivo puro conteniendo $10^{8}$ leptospiras patógenas de la especie L. borgpetersenii, serogrupo Ballum, concentración en orina que ha sido reportada por otros autores en $900 \mu 1$ de orina (Adler y de la Peña Moctezuma, 2010). Para obtener esa cantidad de leptospiras se utilizó la equivalencia entre número de estas y la densidad óptica, tomando como referencia que una concentración de $7 \times 10^{8}$ leptospiras $/ \mathrm{ml}$ de EMJH es equivalente a una densidad óptica de 0.2-0.35 a $420 \mathrm{~nm}$ de longitud de onda (Louvel y Picardeau, 2007; Instituto Nacional de Salud, Perú, datos no publicados). El ADN de la orina infectada fue extraído utilizando el protocolo previamente optimizado. 
Cuadro 2. Bacterias utilizadas en la estandarización de la PCR en tiempo real con sondas TaqMan

\begin{tabular}{ll}
\hline Especie & Código \\
\hline $\begin{array}{l}\text { Staphylococcus aureus } \\
\text { Enterococcus faecalis }\end{array}$ & ATCC 25923 \\
ATCC 29212 \\
$\begin{array}{l}\text { aureginosa } \\
\text { Escherichia coli }\end{array}$ & ATCC 27853 \\
Pasteurella multocida & NE 49 25922 \\
\hline
\end{tabular}

Otros géneros bacterianos

La especificidad de la técnica de PCR en la detección de Leptospira spp fue evaluada utilizando otros géneros bacterianos. Se cultivaron cepas patrón de los géneros Staphylococcus, Pseudomonas, Enterococcus, Pasteurella y Escherichia (Cuadro 2). La extracción de ADN se realizó de acuerdo a las especificaciones del kit comercial Wizard ${ }^{\circledR}$ Genomic DNA Purification (Promega).

El producto de ADN extraído fue visualizado en un gel de agarosa al $1 \%$ teñido con SYBR Safe (Invitrogen) por electroforesis a $90 \mathrm{~V}$ durante $60 \mathrm{~min}$ y visualizado en un transiluminador Ultra Lum. Para la corrida electroforética se utilizó un marcador de peso molecular de 50-3000 pb (GeneON, Alemania).

\section{Estandarización de la PCR en Tiempo Real}

\section{Cebadores y sondas TaqMan}

Se utilizaron los cebadores Lepto R y Lepto F, específicos para Leptospira spp y las sondas TaqMan Lepto probe, capaces de diferenciar entre especies patógenas y no patógenas (Smythe et al., 2002).
Los cebadores Lepto F (5 $5^{171}$ CCCGCGTCCGATTAG $3^{\prime}$ ) y Lepto R (5'258 TCCATTGTGGCCGR ${ }^{\mathrm{A} / \mathrm{G}} \mathrm{ACAC} 3^{\prime}$ ) se encuentran entre las posiciones 171 y $258 \mathrm{del}$ gen $r$ rs (codifica la síntesis del fragmento $16 \mathrm{~S}$ del ARNr) y amplifican productos de $87 \mathrm{pb}$.

La sonda específica $\left[5^{205}\right.$ (FAM) CTCACCAAGGCGACGATCGGTAGC ${ }^{228}$ 3 '(TAMRA)] está diseñada para hibridar una porción del segmento del gen $r r s$, generado por los cebadores Lepto F y Lepto R, solo en las leptospiras patógenas.

\section{Condiciones de la PCR}

Durante la estandarización, se utilizó ADN extraído de los 25 serogrupos patógenos como controles positivos, en diluciones de $10^{7}$ a $10^{\circ} \mathrm{con}$ agua ultrapura, para determinar el grado de precisión de la prueba. La especie saprófita $L$. biflexa, los otros géneros bacterianos y el mix sin ADN fueron utilizados como controles negativos.

Para preparar el mix de PCR se utilizó el GoTaq® Probe qPCR Master Mix (Promega) a una concentración final de $1 \mathrm{X}$, que incluye una polimerasa «hot start», junto con los cebadores Lepto F y Lepto R en concentraciones finales de $0.03 \mu \mathrm{M}$ y la sonda Lepto probe a una concentración de $0.02 \mu \mathrm{M}$, agua ultrapura y $\mathrm{ADN}$ molde que representó el $10 \%$ del volumen total $(2 \mu \mathrm{l})$. El volumen de reacción fue de $20 \mu$ l.

Se evaluaron 3 protocolos de 40, 35 y 30 ciclos, con una desnaturalización inicial a $95{ }^{\circ} \mathrm{C}$ durante $5 \mathrm{~min}$, consistiendo cada ciclo de una desnaturalización a $95{ }^{\circ} \mathrm{C}$ por $15 \mathrm{~s} \mathrm{y}$ un alineamiento/extensión a $60^{\circ} \mathrm{C}$ por $1 \mathrm{~min}$. La reacción se llevó a cabo en el sistema a tiempo real que incluye el termociclador PTC 200 (MJ Research) y el equipo Chromo-4 ${ }^{\mathrm{TM}}$ (BIORAD) como lector de emisión de fluorescencia. 


\section{Análisis de los Resultados}

Se analizaron los valores de $\mathrm{Ct}$ (ciclo de amplificación) obtenidos mediante el software Opticon Monitor 2 v. 2.0.3. La eficiencia de la amplificación promedio (E) fue determinada a partir de la pendiente obtenida de las concentraciones producidas por triplicado para el experimento utilizando la ecuación $\mathrm{E}=\left(10^{-1 / \text { pendiente }}\right)-1$.

\section{Resultados y Discusión}

Diversos ensayos de PCR en tiempo real han sido descritos para el diagnóstico de leptospirosis (Levett et al., 2005; Merien et al., 2005; Palaniappan et al., 2005; Roczek et al., 2008; Stoddard et al., 2009; Rojas et al., 2010), pero pocos han sido validados para su uso diagnóstico en muestras de animales (Smythe et al., 2002; Slack et al., 2007; Ahmed et al., 2009).

La sedimentación de leptospiras para la extracción de $\mathrm{ADN}$ es un punto crítico en la optimización del protocolo de extracción. Por ello, se probaron protocolos de extracción con diferentes velocidades de sedimentación (3000 $\mathrm{g}$ por $20 \mathrm{~min}$ hasta $16000 \mathrm{~g}$ por 25 min), encontrándose mejores resultados con la mayor velocidad y tiempo de centrifugación. Esto ya ha sido descrito por otros autores que mencionan que la extracción de ADN leptospiral es relativamente difícil debido a que las leptospiras no sedimentan fácilmente (Faine et al., 1999; Picardeau et al., 2001; Serrano, 2012).

Uno de los pasos claves en el éxito en la extracción de ADN es la ruptura de la membrana de la bacteria y su protección del daño de los cristales que puedan estar presentes en la orina (Fonseca et al., 2005). Por ello, se optimizó el protocolo de extracción utilizando las enzimas proteolíticas lisozima y proteinasa $\mathrm{K}$, asociado a un tratamiento con calor a 37 y $55{ }^{\circ} \mathrm{C}$, respectivamente (Verkooyen et al., 1996). Se encontró que la
Cuadro 3. Valores de ciclo de amplificación (Ct) de los productos obtenidos de 25 cepas patógenas de referencia, una cepa saprófita y otros géneros bacterianos

\begin{tabular}{lcc}
\hline Leptosipra & $\mathrm{Ct}$ & + /- \\
\hline L. interrogans Canicola & 12.53 & + \\
L. interrogans Australis & 12.59 & + \\
L. interrogans Pomona & 13.05 & + \\
L. kischneri Grippotyphosa & 13.20 & + \\
L. interrogans Autumnalis & 13.21 & + \\
L. interrogans Pyrogenes & 13.21 & + \\
L. interrogans Hebdomadis & 13.23 & + \\
L. licerasiae Iquitos & 13.25 & + \\
L. weilii Celledoni & 13.52 & + \\
L. kirschneri Cynopteri & 13.99 & + \\
L. interrogans & 14.08 & + \\
$\quad$ Icterohaemorrhagiae & & \\
L. santarosai Shermani & 14.08 & + \\
L. interrogans Bataviae & 14.09 & + \\
L. borgpetersenii Ballum & 14.09 & + \\
L. noguchii Louisiana & 14.25 & + \\
L. weilii Sarmin & 14.42 & + \\
L. santarosai Mini & 14.63 & + \\
L. borgpetersenii Tarassovi & 14.65 & + \\
L. faine Hurstbridge & 14.72 & + \\
L. interrogans Sejroe & 16.41 & + \\
L. interrogans Djasiman & 16.73 & + \\
L. meyeri Ranarum & 17.29 & + \\
L. borgpetersenii Javanica & 17.98 & + \\
L. interrogans Manhao & 18.17 & + \\
L. noguchii Panama & 18.21 & + \\
L. biflexa Semaranga & $\mathrm{NCt}$ & - \\
Pseudomonas aureginosa & $\mathrm{NCt}$ & - \\
Pasteurella multocida & $\mathrm{NCt}$ & - \\
Staphylococcus aureus & $\mathrm{NCt}$ & - \\
Enterococcus faecalis & $\mathrm{NCt}$ & - \\
Escherichia coli & $\mathrm{NCt}$ & - \\
\hline & &
\end{tabular}

extracción del ADN mejoró al utilizar lisozima en concentración de $50 \mathrm{mg} / \mathrm{ml}$.

A pesar que Leptospira sp es una bacteria Gram negativa, se requiere adicionar enzimas proteolíticas para la destrucción de la membrana y la liberación del ADN. Esto podría ser debido a la estructura de la membrana de la bacteria. Al igual que en las Gram 


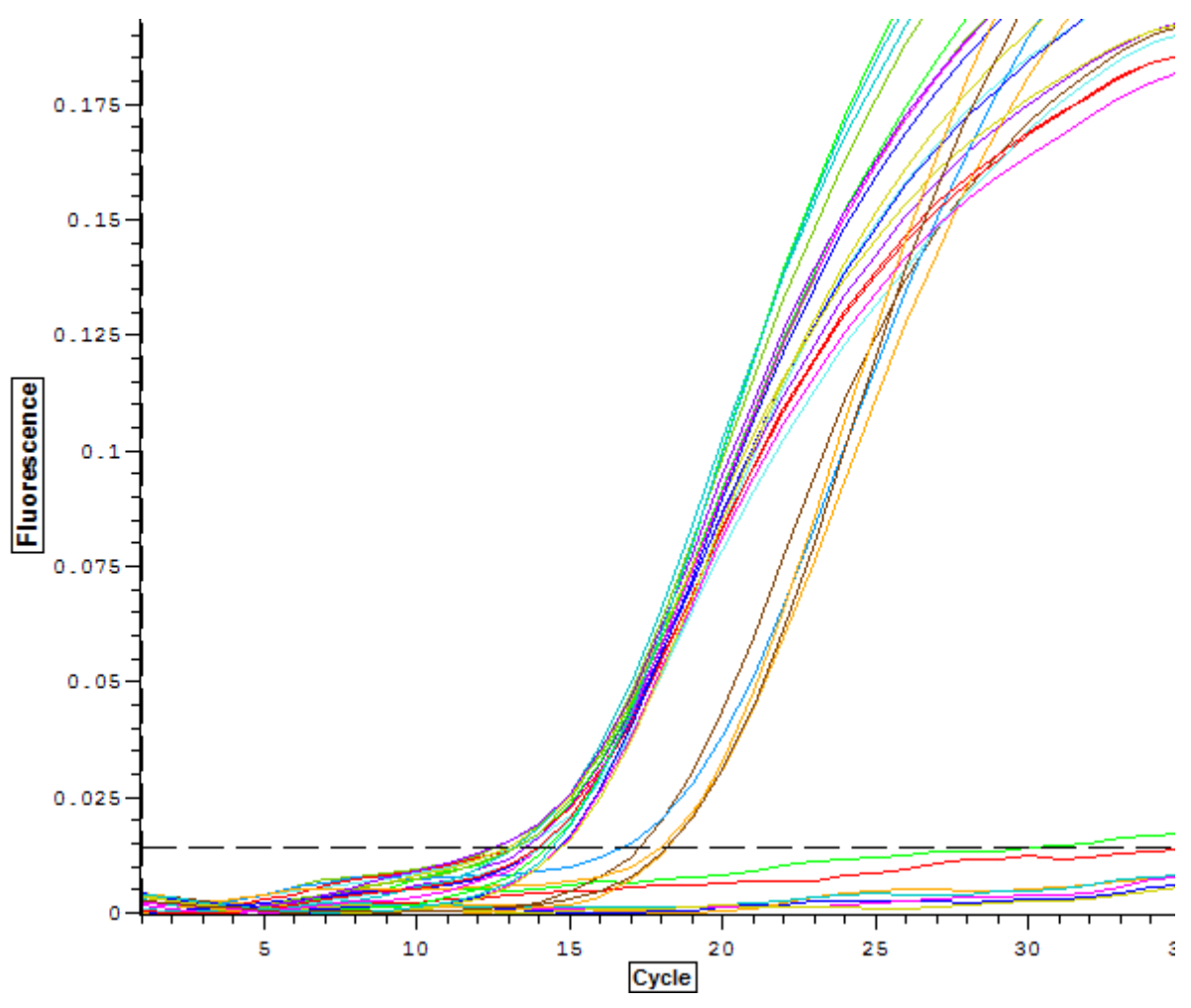

Figura 1. Valores del ciclo de amplificación (Ct) de las 25 cepas patógenas de Leptospira sp. Los controles positivos presentan valores de Ct entre 18.21 y 12.53 , a diferencia del resto de controles negativos que no superan el umbral

positivas, la membrana citoplasmática interna de las espiroquetas está estrechamente asociada con la pared celular de peptidoglicano (Haake y Matsunaga, 2009).

En el proceso de estandarización de la PCR, los valores del ciclo de amplificación (Ct) fueron desde 12.53 hasta 18.21 para los 25 serovares patógenos de Leptospira, mostrando una marcada diferencia con la cepa saprófita $L$. biflexa y con los controles negativos y otros géneros bacterianos que no generaron amplificados que excedieran el umbral, con el protocolo de 35 ciclos (Cuadro 3, Fig. 1); demostrándose de esta manera la especificidad de la prueba para detectar solo leptospiras patógenas. Por otro lado, los valores de $\mathrm{Ct}$ obtenidos fueron diferentes a los obtenidos por Smythe et al. (2002) utilizando los mismos cebadores y sonda, los cuales obtuvieron valores de $\mathrm{Ct}$ entre 18.20 y 23.40 en 40 ciclos a partir de muestras de sangre de pacientes humanos (Smythe et al., 2002). Estas variaciones pueden deberse a las diferentes concentraciones de ADN presentes en las muestras, así como a la naturaleza de las mismas. Otros aspectos a considerar son el uso de diferentes kits de extracción y las marcas y características de los equipos, así como diversos protocolos que pueden producir resultados variables.

Las diluciones del estándar de los cultivos de leptospira $\left(10^{7}-10^{\circ}\right)$ fueron detectadas con unos valores de $\mathrm{Ct}$ desde 16.49, para la dilución de $10^{7}$, hasta 29.98 que corresponde a una dilución de $10^{2}$ leptospiras. Este intervalo de $10^{7}$ a $10^{2}$ describió una curva de calibración con una eficiencia de 1.13 y un coeficiente de correlación $\left(\mathrm{R}^{2}\right)$ de 0.993 que 


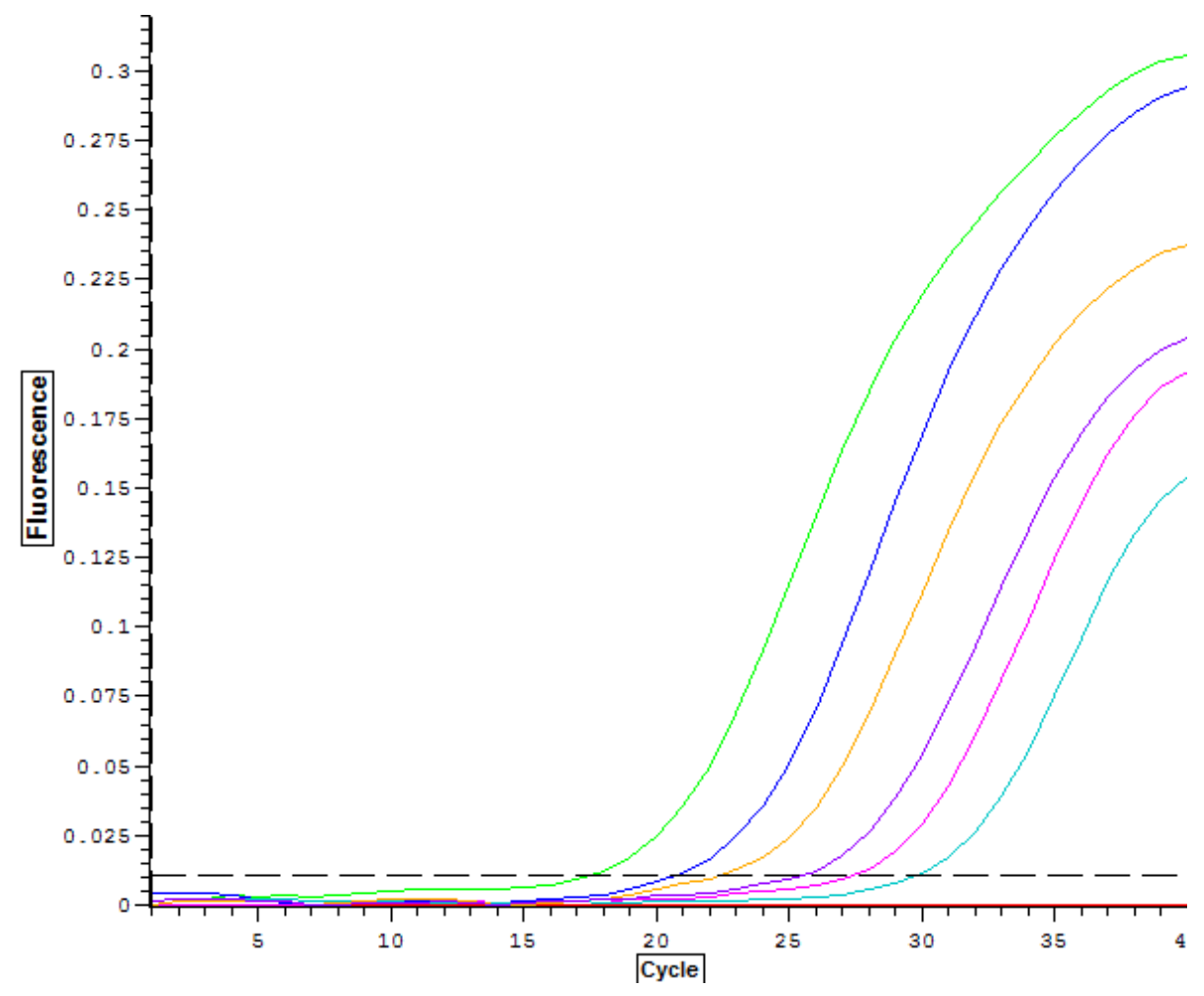

Figura 2. Valores del ciclo de amplificación (Ct) de las diluciones de la orinas infectadas con una cepa patógena de Leptospira (serogrupo Ballum). Se observan las diluciones de $10^{7}$ hasta $10^{2}$, siendo $10^{2}$ el límite de detección

es lo óptimo para esta prueba (Wang et al., 2012). Las diluciones de $10^{1}$ y $10^{0}$ con $\mathrm{Ct}$ de 34.05 y 34.40 , respectivamente, tuvieron una curva muy débil, por lo que se consideró que mediante el protocolo implementado se cuantifica la concentración de leptospiras hasta un orden mínimo de $10^{2}$. Por esta razón, el protocolo de PCR se optimizó en 35 ciclos (Cuadro 4).

De la misma manera, el ADN leptospiral en las muestras de orina detectado hasta en una dilución de $10^{2}$ leptospiras con un valor de $\mathrm{Ct}$ de 29.87 se encuentra en el rango del estándar (Fig. 2). Las diluciones de $10^{1}$ y $10^{0}$ no generaron productos específicos. El presente protocolo logró detectar ADN de Leptospira sp patógena a partir de una concentración de $10^{2}$ leptospiras $/ \mathrm{ml}$, el cual se determinó como el mínimo nivel de detección de la prueba.

\section{Conclusiones}

- La presente técnica de PCR en tiempo real con sondas TaqMan permite detectar cepas patógenas del género Leptospira en orina de canes domésticos, permitiendo detectar hasta $10^{2}$ leptospiras/ml.

- La velocidad y el tiempo de centrifugación son factores importantes para el éxito en la extracción de ADN de Leptospira spp. 
Cuadro 4. Valores de ciclo de amplificación (Ct) de los productos obtenidos en PCR tiempo real de las diluciones decrecientes de una cepa patógena de Leptospira (serogrupo Autumnalis) y otras especies de bacterias

\begin{tabular}{cc}
\hline $\begin{array}{l}\text { Diluciones de ADN de } L . \\
\text { interrogans Autumnalis y }\end{array}$ & $\mathrm{Ct}$ \\
ADN de controles negativos & \\
\hline $10^{7}$ & 16.49 \\
$10^{6}$ & 20.34 \\
$10^{5}$ & 23.21 \\
$10^{4}$ & 26.26 \\
$10^{3}$ & 28.62 \\
$10^{2}$ & 29.97 \\
$10^{1}$ & 32.55 \\
$10^{0}$ & 34.05 \\
L biflexa Semaranga & 34.03 \\
Staphylococcus aureus & 34.09 \\
Enterococcus faecalis & 34.11 \\
Pseudomonas aureginosa & 34.13 \\
Pasteurella multocida & 34.37 \\
Escherichia coli & 34.40 \\
\hline
\end{tabular}

\section{Literatura Citada}

1. Acha PN, Szyfres B. 2003. Leptospirosis. En: Zoonosis y enfermedades transmisibles comunes al hombre y a los animales. Vol. I. Bacteriosis y Micosis. $3^{\mathrm{a}}$ ed. Publicación Científica y Técnica No. 580. Washington, EEUU: Organización Panamericana de la Salud. p 175-186.

2. Adler B, De la Peña Moctezuma A. 2010. Leptospira and leptospirosis. Vet Microbiol 140: 287-297. doi: 10.1016/ j.vetmic.2009.03.012

3. Ahmed A, Engelberts MF, Boer KR, Ahmed N, Hartskeerl RA. 2009. Development and validation of a real- time PCR for detection of pathogenic Leptospira species in clinical materials. PLoS One 4(9): e7093. doi: 10.1371/ journal.pone.0007093

4. Blum S, Chi M, Maldonado M, Nuñez L, Gómez M, Caballero R, Tamay P. 2013. Detection of reactive canines to Leptospira in Campeche City, Mexico. Rev Argent Microbiol 45: 34-38.

5. Brown PD, Gravekamp C, Carrington DG Van de Kemp H, Hartskeerl RA, Edwards CN, Everard CO, et al. 1995. Evaluation of the polymerase chain reaction for early diagnosis of leptospirosis. J Med Microbiol 43: 110114.

6. Céspedes M. 2005. Leptospirosis: enfermedad zoonótica reemergente. Rev Peru Med Exp Salud Pública 22: 290307.

7. Espy M, Uhl JR, Sloan L, Buckwalter $S$, Jones $M$, Vetter E, et al. 2006. Realtime PCR in clinical microbiology: applications for routine laboratory testing. Clin Microbiol Rev 19: 165-256. doi: 10.1128/CMR.19.1.165-256.2006

8. Cole J, Sulzer C, Pursell A. 1973. Improved microtechnique for the leptospiral microscopic agglutination test. Appl Microbiol 25: 976-980.

9. Faine S, Adler B, Bolin C, Perolat P. 1999. Leptospira and Leptospirosis. $2^{\text {nd }}$ ed. Melbourne. MediSci. 272 p.

10. Fonseca D, Gutiérrez A, Mateus H, Silva C, Contreras N, Giraldo A. 2005. Análisis de muestras de orina para la detección molecular de enfermedades infecciosas. Aplicación en la identificación de citomegalovirus humano. Rev Ciencias Salud 3: 136-147.

11. Haake DA, Matsunaga J. 2005. Leptospiral membrane proteins variations on a theme? Indian J Med Res 121: 143-145.

12. Hartskeel R, Collares-Pereira M, Ellis W. 2001. Emergence, control and reemerging leptospirosis; dynamics of infection in the changing world. Clin Microbiol Infect 17: 494-501. doi: 10.1111/j.1469-0691.2011.03474.x 
13. Hartskeel RA. 2005. International Leptospirosis Society. Objectives and achievements. Rev Cub Med Trop 57: 7-10.

14. Levett PN. 2001. Leptospirosis. Clin Microbiol Rev 14: 296-326.

15. Levett PN, Morey RE, Galloway RL, Turner DE, Steigerwalt AG, Mayer LW. 2005. Detection of pathogenic leptospires by real-time quantitative PCR. J Med Microbiol 54: 45-49.

16. Louvel H, Picardeau M. 2007. Genetic manipulation of Leptospira biflexa. Curr Protoc Microbiol 12: 12-14. doi: 10.1002/9780471729259.mc12e04s05

17. McBride A, Athanazio D, Reis M, Ko A. 2005. Leptospirosis. Curr Opin Infect Dis 18: 376-386.

18. Mendes V, Simoes M, Barbosa A, Navegantes $W$. 2011. Years of potencial life lost and hospitalization costs associated with leptospirosis in Brazil. Rev Saúde Pública 45: 1001-1008.

19. Merien F, Amouriaux P, Perolat P, Baranton G, Saint Girons I. 1992. Polymerase chain reaction for detection of Leptospira spp in clinical samples. J Clin Microbiol 30: 2219-2224.

20. Merien F, Portnoi D, Bourhy P, Charavay $F$, Berlioz-Arthaud A, Baranton G. 2005. A rapid and quantitative method for the detection of Leptospira species in human leptospirosis. FEMS Microbiol Lett 249: 139-147. doi: 10.1016/j.femsle.2005.06.011

21. Musso D, La Scola B. 2013. Laboratory diagnosis of leptospirosis: A challenge. J Microbiol Immunol Infect 46: 245-252. doi: http://dx.doi.org/ 10.1016/j.jmii.2013.03.001

22. Navarrete J, Acevedo J, Huerta E, Torres J, Gavaldón D. 2006. Prevalencia de anticuerpos contra dengue y leptospira en la población de Jáltipan, Veracruz. Sal Pub Mex 48: 220-228.

23. [OIE] World Organisation for Animal Health. 2014. Leptopsirosis. Ch 2.1.9. OIE Terrestrial Manual 2014. [Internet]. Disponible en: http://www.oie.int/ fileadmin/Home/eng/Health_standards/ tahm/2.01.09_LEPTO.pdf
24. [OMS] Organización Mundial de la Salud. 2008. Leptospirosis humana: guía para el diagnóstico, vigilancia y control. Rio de Janeiro: Centro Panamericano de Fiebre Aftosa. 127 p.

25. Palaniappan R, Chang Y, Chang $C$, Pan $M$, Yang $C$, Harpending $P$, McDonough $S$, et al. 2005. Evaluation of lig-based conventional and real time PCR for the detection of pathogenic leptospires. Mol Cell Probes 19: 111-117. doi: 10.1016/j.mcp.2004.10.002

26. Picardeau M, Brenot A, Saint Girons I. 2001. First evidence for gene replacement in Leptospira spp inactivation of L. biflexa flaB results in nonmotile mutants deficient in endoflagella. Mol Microbiol 40: 189-199.

27. Roczek A, Forster C, Raschel H, Hormansdorfer $S$, Bogner KH, Hafner-Marx A, Lepper $H$, et al. 2008. Severe course of rat bite associated Weil's disease in a patient diagnosed with a new Leptospiraspecific real-time quantitative LUXPCR. J Med Microbiol 57: 658-663. doi: 10.1099/jmm.0.47677-0

28. Rojas P, Monahan AM, Schuller S, Miller I, Markey B, Nally J. 2010. Detection and quantification of leptospires in urine of $\operatorname{dogs}$ : a maintenance host for the zoonotic disease leptospirosis. Eur J Clin Microbiol Infect Dis 29: 1305-1309. doi: $10.1007 / \mathrm{s} 10096-$ 010-0991-2

29. Romero M, Sánchez V. 2009. Seroprevalencia de Leptospirosis canina de tres municipios del departamento del TolimaColombia. Rev MVZ Córdoba 14: 16841689.

30. Serrano M. 2012. Exposición a Leptospira spp patógena del elefante marino, Mirounga aungustirostris. Tesis de Maestría. México: Universidad Autónoma de Baja California. 134 p.

31. Slack A, Symonds M, Dohnt M, Harris C, Brookes D, Smythe L. 2007. Evaluation of a modified Taqman assay detecting pathogenic Leptospira spp against culture and Leptospira specific 
IgM enzyme-linked immunosorbent assay in a clinical environment. Diagn Microbiol Infect Dis 57: 361-366. doi: 10.1016/j.diagmicrobio.2006.10.004

32. Smythe L, Smith I, Smith G., Dohnt $M$, Symonds M, Barnett L, McKay D. 2002. A quantitative PCR (TaqMan) assay for pathogenic Leptospira spp. BMC Infect Dis 2: 13-20. doi: 10.1186/ 1471-2334-2-13

33. Stoddard R, Gee J, Wilkins P, McCaustland K, Hoffmaster A. 2009. Detection of pathogenic Leptospira spp. through TaqMan polymerase chain reaction targeting the LipL32 gene. Diagn Microbiol Infect Dis 64: 247-255. doi: 10.1016/j.diagmicrobio.2009.03.014

34. Vargas E. 2014. Situación de la leptospirosis en el Perú, años 2013-2014 (a la SE 19). Bol Epidemiol (Lima) 23(19): 382-385.
35. Verkooyen R, Luijendijk W, Huisman W, Goessesns J. 1996. Detection of PCR inhibitors in cervical specimens by using the AMPLICOR Chlamydia tracho-matis assay. J Clin Microbiol 34: 3072-3074.

36. Villumsen S, Pedersen $R$, Krogfelt $K$, Jensen J. 2010. Expanding the diagnostic use of PCR in leptospirosis: improved method for DNA extraction from blood cultures. PLoS One 5(8):e12095. doi: 10.1371/journal.pone.0012095

37. Wang $C$, Freeman $M$, Kaltenboeck $B$. 2012. Veterinary PCR diagnostics. USA: Bentham Ebooks. 137 p.

38. [WHO] World Health Organization International. 2003. Human Leptospirosis: guidance for diagnosis, surveillance and control. Malta: WHO. 109 p. 